\title{
Correspondence
}

\section{The concepts of assent and parental permission in pediatrics}

$\mathrm{T}$ The recently published article by Narchi et a ${ }^{[1]}$ brings an important empirical insight into a very complex issue of parental consent for lumbar puncture (LP) in children; quite worrisome observation from authors' clinical practice that almost half of the parents refused to give consent for the LP is confirmed. ${ }^{[1]}$

However, the concept of (parental) consent, used by Narchi et al, ${ }^{[1]}$ would need to be further elaborated with introduction of two other important concepts in pediatrics-child's assent and parental permission. The concepts were endorsed by the policy statement of the American Academy of Pediatrics (published in 1995; reaffirmed in 2011). ${ }^{[2]}$ Accordingly, only the patients with appropriate decisional capacity could give their informed consent. In all other situations, parents provide informed permission for an intervention on their child, with assent of the child if appropriate. ${ }^{[2]}$ Most of children from age seven are thought to understand basic information if adequately presented. ${ }^{[3]}$ The need for assent was also supported by the Confederation of European Specialists in Pediatrics, stating that all children have a right to give their assent (or dissent) and may refuse interventions that are not necessary to save their lives or prevent serious harm. ${ }^{[4]}$ Furthermore, the responsibility to make decision in children is shared between physicians and parents. The later should provide informed permission before interventions (except in emergency situations), which includes all the elements of informed consent, reflecting the child's best interests. ${ }^{[2]}$

Informed permission should be sought for the nonurgent LP, if it is medically indicated. ${ }^{[2]}$ Indeed, as suggested by Narchi et al, ${ }^{[1]}$ a better understanding of the perceptions, beliefs and fears of parents is useful for developing appropriate solutions to prevent their refusal to the LP. ${ }^{[1]}$ However, it is necessary to add, that also child's assent to the non-urgent LP (according to one's age/mental development) should be sought as eagerly as should be parental permission.

\author{
Urh Groselj \\ Department of Pediatric Endocrinology, \\ Diabetes and Metabolic Diseases, \\ University Children's Hospital Ljubljana, \\ and National Medical Ethics Committee of Slovenia \\ Ljubljana, Slovenia \\ Email:urh.groselj@kclj.si
}

\section{References}

1 Narchi H, Ghatasheh G, Hassani NA, Reyami LA, Khan Q. Comparison of underlying factors behind parental refusal or consent for lumbar puncture. World J Pediatr 2013;9:336-341.

2 American Academy of Pediatrics, Committee on Bioethics. Informed consent, parental permission, and assent in pediatric practice. Pediatrics 1995;95:314-317.

3 Wendler DS. Assent in paediatric research: theoretical and practical considerations. J Med Ethics 2006;32:229-234.

4 De Lourdes Levy M, Larcher V, Kurz R; Ethics Working Group of the Confederation of European Specialists in Paediatrics (CESP). Informed consent/assent in children. Statement of the Ethics Working Group of the Confederation of European Specialists in Paediatrics (CESP). Eur J Pediatr 2003;162:629633.

doi: $10.1007 / \mathrm{s} 12519-014-0460-6$

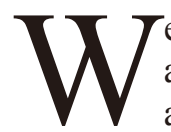
e thank Dr. Groselj for his interest in our article and his comments. Although we always provided full information before obtaining parental consent for the intervention, he raised the issue of child's assent and parental permission. ${ }^{[1]}$ He suggested that only the patients with appropriate decisional capacity could give their informed consent; in all other situations, parents should provide informed permission for an intervention on their child, with the child's assent, if appropriate The child, however, has a right to refuse interventions that are not necessary to save his/her life or prevent serious harm. ${ }^{[2]}$ The implication is that the child's assent, assuming its appropriateness can be easily assessed, should overide the parents' decision, if it can clearly be established that they lack the appropriate decisional capacity. This is in sharp contrast with the same American Academy of Pediatrics (AAP) document which he cited, and which, interestingly, refers specifically to parents refusing diagnostic lumbar puncture, which has perhaps escaped Dr. Groselj's attention. It specifically advises that the physician should obtain parental permission to initiate the appropriate treatment rather than delaying care or risking liability for performing that procedure without appropriate authorization. ${ }^{[1]}$ This is why we do not agree with his suggestion and opts to remain compliant with the AAP statement.

We embarked on the study to better understand the specific barriers for LP consent in our own environment. The law governing consent issues in the country where the study was held specifically gives the authority of consent to the parents until the child is 18 years old, as until then, he/she is considered as 